\title{
HEPATIC DYSFUNCTION IN DENGUE FEVER- A PROSPECTIVE STUDY DONE AT A TERTIARY CARE HOSPITAL, SHIMOGA
}

\author{
Malavade Praveen ${ }^{1}$, Girish I ${ }^{2}$ \\ ${ }^{1}$ Senior Resident, Department of General Medicine, SIMS, Shimoga. \\ ${ }^{2}$ Assistant Professor, Department of General Medicine, SIMS, Shimoga.
}

ABSTRACT
BACKGROUND
Dengue is a major health concern, especially in tropical country like India. Hepatic dysfunction in dengue fever is a common feature
which complicates the clinical course of the infection and worsen the prognosis. This study was done to assess the frequency and
spectrum of liver dysfunction in Dengue infection patients.

\section{MATERIALS AND METHODS}

It was a prospective observational study done in Vaatsalya Hospital, Shimoga, for the duration of 6 months, i.e. from 16/05/2017 to $15 / 11 / 2017$. All patients attending Vaatsalya Hospital, Shimoga with positive serological tests were included in the study after taking written informed consent. Complete blood count and LFT were done and severity of hepatic dysfunction was based on the extent to which ALT and AST were elevated.

\section{RESULTS}

$100 \%$ of patients had elevated AST, 100\% patients had elevated AST and 85\% patients had elevated ALT. The albumin level was low in $75 \%$ patients. Average AST was 316 units/L and average ALT was 156 units/L.

\section{CONCLUSION}

Hepatic involvement in dengue is universal. AST elevation is more common than ALT elevation. Reversal of AST to ALT ratio along with high-grade fever and constitutional symptoms may help in early diagnosis of dengue.

\section{KEYWORDS}

Dengue Fever, Hepatic Dysfunction, AST, ALT, Thrombocytopenia.

HOW TO CITE THIS ARTICLE: Praveen M. Girish I, Hepatic dysfunction in dengue fever- a prospective study done at a tertiary care hospital, Shimoga. J. Evolution Med. Dent. Sci. 2018;7(01):50-52, DOI: 10.14260/jemds/2018/13

\section{BACKGROUND}

Dengue infection is an arthropod-borne viral infection caused by flavivirus and transmitted by Aedes Aegypti mosquito. ${ }^{1}$ It is the second most common cause of vector-borne febrile illness next to malaria and in the recent years number of cases were reported to have drastically increased and it has become a major public health issue. ${ }^{2}$ According to WHO estimation, presently about two-fifths of the world population is at risk for this viral infection. ${ }^{3}$ Patients present with various symptoms which include high-grade fever, chills, backache, arthralgia, myalgia, headache, abdominal pain, vomiting, sore throat, conjunctival congestion, maculopapular rashes and petechiae. Depending on the severity of symptoms it can be classified into dengue fever, dengue haemorrhagic fever and dengue shock syndrome. In almost all cases of dengue, liver is affected in variable severity ranging from asymptomatic raise of liver enzymes to acute fulminant hepatitis. However, there are only few prospective studies which has documented hepatic involvement and degree of hepatic injury in dengue fever. Hence, in our study we aim to assess the hepatic involvement and degree of hepatic injury in dengue fever.

'Financial or Other Competing Interest': None.

Submission 04-12-2017, Peer Review 18-12-2017,

Acceptance 20-12-2017, Published 01-01-2018.

Corresponding Author:

Dr. Girish $I$

S/o. Iyyanna $S$, $3^{\text {rd }}$ Cross,

Nehru Nagar, Chitradurg-577501.

E-mail: drgirishiyyanna@gmail.com

DOI: $10.14260 /$ jemds $/ 2018 / 13$

\section{(c) $(1) \$$}

\section{Review of Literature}

Gandhi $\mathrm{K}$ and M Shetty evaluated 53 patients with dengue fever in KMC Mangalore, out of which 27 patients were serologically positive and found that $85 \%$ of patients had at least one of the aminotransferases high. AST elevation was raising quickly and was peaking higher than ALT.4

$S$ Fernando et al evaluated 55 adult patients with dengue fever. These patients were subjected for serial monitoring of liver function tests, viral loads and found that AST, ALT and GGT were raised in all patients and peak level was found on $6^{\text {th }}$ day. ${ }^{5}$

Itha $S$ et al evaluated 45 patients with dengue fever which included 23 uncomplicated dengue fever with 15 dengue haemorrhagic fever and 7 with dengue shock syndrome. In their study seven patients (15\%) had jaundice, 11 (24\%) had hepatomegaly and 9 had clinically detectable ascites. ALT and AST were elevated in $96 \%$ of patients and there was no specific raise of one enzyme and magnitude of elevation of both enzymes were comparable. $76 \%$ of patients had hypoalbuminemia. ${ }^{6}$

Vaibhav Shukla and Ashok Chandra evaluated patients with dengue fever. In their study $100 \%$ patients had an elevated SGOT level, while 91\% patients had elevated SGPT level. $85 \%$ of patients had their SGOT level more than two times of the normal range, while $48 \%$ patients had SGPT levels more than two times of the normal range. Inpatients with both aminotransferase raised, the SGOT levels were 2 - 3 times higher than SGPT levels. $50 \%$ of patients had hepatomegaly. ${ }^{7}$ 


\section{Aims and Objectives}

To study hepatic function derangement in dengue fever.

\section{MATERIALS AND METHODS}

It is a prospective observational study done in Vaatsalya Hospital, Shimoga for the duration of 6 months, i.e. from $16 / 05 / 2017$ to $15 / 11 / 2017$. All patients attending Vaatsalya Hospital, Shimoga with history of high-grade fever for minimum of 3 days' duration with constitutional symptoms were subjected for complete blood count test, LFT and dengue antigen and serological test. Patients with positive serological test were included in the study after taking written informed consent. Patients younger than 15 years and older than 70 years and patients with history of hepatitis, alcoholics, history of pre-existing liver disease were excluded from the study. Severity of hepatic dysfunction was based on the extent to which ALT and AST were elevated and were classified into four groups. It was considered normal when AST and ALT were $40 \mathrm{U} / \mathrm{L}$. Patients with normal values were assigned Group 1, patients with elevated ALT or AST or both but less than three times the normal range were assigned Group 2. Patients with raised ALT or AST or both more than three times the normal range, but less than ten times were assigned Group 3. Patients with raised ALT or AST or both more than ten times the normal range were assigned Group 4.

\section{RESULTS}

60 patients were included in the study, out of which 40 (66.6\%) were males and $20(33.3 \%)$ were females. Mean age of presentation was 36 years, most of them were in the age group of 15 to 45 years. 27 (45\%) patients had clinically enlarged liver, $16(26.6 \%)$ had leukopenia. 4 (6.6\%) patients had mild raise in total bilirubin. Average platelet count was found to be 42000 and $6(10 \%)$ patients had platelet count less than 20,000 and required platelet transfusion. $3(5 \%)$ patients had bleeding manifestation. None of the patients had fulminant hepatitis. No patient died.

All patients had elevated AST, 51 (85\%) patients had elevated ALT. The albumin level was low in 45 (75\%) patients. Average AST was 316 units/L and average ALT was 156 units/L.

In our study 27 (45\%) patients were under Group 2; 5 (41.6\%) patients were under Group 3; and 8 (13.3\%) patients were classified under Group 4.

\begin{tabular}{|c|c|c|}
\hline Parameters & Results & P value \\
\hline Age & 36 & \\
\hline Platelets (cells/mm ${ }^{3}$ ) & 42000 & $\mathrm{P}<0.0003$ \\
\hline Total bilirubin (mg/dL) & 1.3 & $\mathrm{P}=0.3$ \\
\hline Direct bilirubin (mg/dL) & 0.8 & $\mathrm{P}=0.18$ \\
\hline Total protein (g/dL) & 6.38 & $\mathrm{P}=0.0015$ \\
\hline Albumin (g/dL) & 3.8 & $\mathrm{P}=0.028$ \\
\hline Globulin (g/dL) & 2.76 & $\mathrm{P}=0.032$ \\
\hline AST (U/L) & 316 & $\mathrm{P}=0.028$ \\
\hline ALT (U/L) & 156 & $\mathrm{P}=0.032$ \\
\hline ALP (U/L) & 96.74 & $\mathrm{P}=0.064$ \\
\hline Table 1. Liver Function Profile in Our Study Group \\
\hline
\end{tabular}

\section{DISCUSSION}

In our study, all patients had hepatic involvement in various degree. Hepatic dysfunction in paediatric cases are well documented.8,9,10 There are only few prospective studies documenting hepatic dysfunction in dengue. Our study results were similar to previous studies.4,11,12 Most of them had mild-to-moderate dysfunction with few acute hepatitis. None had fulminant hepatitis or dengue shock syndrome.

In our study, all patients had raised AST either alone or along with raised ALT and in cases where both AST and ALT were raised AST was much higher in comparison with levels of ALT. This pattern is usually noticed in alcoholic liver disease. This result is comparable to other studies.5,7 This reversal of AST and ALT is not seen in other forms of viral hepatitis. In a study by Itha $S$ et al, ${ }^{6}$ though there was elevation of hepatic enzymes there was no preferential raise in one enzyme which is in contrast to our study result.

\section{CONCLUSION}

In dengue patients, liver involvement is almost universal. There was no relationship between severity of dengue and severity of dengue fever. But elevation of liver enzymes, specifically reversal of AST and ALT ratio along with highgrade fever and other constitutional symptoms suggesting dengue fever may help in diagnosis of dengue in early cases where serological test is not positive and to differentiate it from other infections mimicking dengue clinically.

\section{ACKNOWLEDGEMENTS}

Authors acknowledge the immense co-operation received by the patients and the help received from the scholars whose articles are included and cited in reference to this manuscript. The authors are also grateful to authors/ editors/ publishers of all those articles, journals and books from where the literature for this article has been reviewed and discussed.

\section{REFERENCES}

[1] Weaver SC. Host range, amplification and arboviral disease emergence. Arch Virol Suppl 2005;(19):33-44.

[2] World Health Organization. Dengue-guidelines for diagnosis, treatment, prevention and control. New edn. Geneva: World Health Organization Publishers, 2009:4-6.

[3] World Health Organization Dengue and Dengue Hemorrhagic fever. www.who.int/mediacentre/factsheets./fs117/en/ Accessed on 29.1.2011.

[4] Fernando S, Wijewickrama A, Gomes L, et al. Patterns and causes of liver involvement in acute dengue infection. BMC Infect Dis 2016;16:319.

[5] Gandhi K, Shetty M. Profile of liver function test in patients with dengue infection in South India. Med J DY Patil Univ 2013;6(4):370-2.

[6] Itha S, Kashyap R, Krishnani N, et al. Profile of liver involvement in dengue virus infection. Natl Med J India 2005;18(3):127-30.

[7] Shukla V, Chandr A. A study of hepatic dysfunction in dengue. J Assoc Physicians India 2013;61(7):460-1.

[8] Roy A, Sarkar D, Chakraborty S, et al. Profile of hepatic involvement by dengue virus in dengue infected children. N Am J Med Sci 2013;5(8):480-5.

[9] Pires Neto Rda J, de Sá SL, Pinho SC, et al. Dengue infection in children and adolescents: clinical profile in a reference hospital in northeast Brazil. Rev Soc Bras Med Trop 2013;46(6):765-8. 


\section{Jemds.com}

[10] Mohan B, Patwari AK, Anand VK. Hepatic dysfunction in childhood dengue infection. J Trop Pediatr 2000;46(1):40-3.

[11] Treeprasertsuk S, Kittitrakul C. Liver complications in adult dengue and management. Southeast Asian J Trop Med Public Health 2015;46(Suppl 1):99-107.

\section{Original Research Article}

[12] Wiwanitkit V. Liver dysfunction in dengue infection: an analysis of the previously published Thai cases. J Ayub Med Coll Abbottabad 2007;19(1):10-2. 